\title{
Radiologic Imaging Procedure
}

National Cancer Institute

\section{Source}

National Cancer Institute. Radiologic Imaging Procedure. NCI Thesaurus. Code C118849.

Any imaging procedure that uses radiation to create an image for the purpose of assisting with the execution of an intervention. 